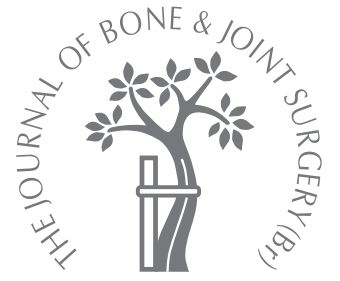

R. Kingma, J. M. Peters, L. N. J. E. M. Coene

From Haga Teaching Hospital, The Hague, The Netherlands

R. Kingma, MD, Orthopaedic Resident

In. M. Peters, MD, Neurology Resident

L. N. J. E. M. Coene, MD, $\mathrm{PhD}$, Orthopaedic Surgeon Haga Teaching Hospital, Leyweg 275, $2545 \mathrm{CH}$, The Hague, The Netherlands.

Correspondence should be sent to Mr R. Kingma; e-mail: renekingma@hotmail.com

C2006 British Editorial Society of Bone and Joint Surgery doi:10.1302/0301-620X.88B12. $17562 \$ 2.00$

$J$ Bone Joint Surg $[\mathrm{Br}]$ 2006;88-B:1654-5.

Received 20 December 2005;

Accepted after revision 25 July 2006

\title{
Intracranial penetration of a halo pin causing an epileptic seizure
}

\author{
A 71-year-old man with ankylosing spondylitis and an unstable fracture of the 6th and 7th \\ cervical vertebrae was managed with a halo vest. Eight weeks following application the \\ halo had shifted because of a loose pin. The patient's only complaint at the time was a \\ headache but this was followed two days later by a seizure. An MR scan of the brain \\ showed a swollen cortex under the right dorsal pin as a result of a perforation of the \\ internal lamina by the pin. The halo was removed and anti-epileptic medication \\ commenced. The patient had no further seizures.
}

The halo vest is commonly used for the conservative management of an unstable cervical spine secondary to fractures, neoplasms, infections, inflammatory arthritis and deformities.

It consists of a titanium frame mounted on a rigid plastic vest surrounding the thorax. The frame is stabilised by attachment to titanium pins placed in the skull. This allows an accurate position of the cervical vertebrae to be maintained and little interference with mandibular function compared with a rigid cervical orthosis. However, the use of the halo vest can lead to complications such as loosening of pins, which is often accompanied by infection at the pinsite. We describe a rare complication following the use of a halo vest and its management.

\section{Case report}

A 71-year-old man with ankylosing spondylitis sustained an unstable fracture of the 6th and 7 th cervical vertebrae following a fall and was treated with a halo vest (Bremer Halo Systems by DePuy Spine; Johnson \& Johnson, Raynham, Massachusetts) with standard titanium pins in the skull. These were tightened with a torque wrench $(0.9 \mathrm{Nm})$ and were checked 24 hours after insertion and then at weekly intervals. In the unlikely event of early loosening, our policy is to re-tighten the pin. In the case of a loose pin we prefer to replace it rather than re-tighten it. In this patient, the pins turned minimally while being tightened to the correct force, so were not considered to be loose at the weekly follow-up. After eight weeks the patient presented at the Emergency Department because the halo had shifted. His only complaint was a severe headache. The halo frame was removed. There was no sign of a pin track infection. However, two days after the removal of the frame, he had a generalised tonic-clonic seizure. Neurological examination showed a minimal left hemiparesis. An MR scan of the brain revealed a traumatic swollen cortex under the right dorsal pin track, with a small subarachnoid haematoma (Fig. 1). Antiepileptic medication (diphantoin) was commenced and continued for three months. $\mathrm{He}$ was discharged with a rigid cervical orthosis and there were no further complications or seizures. Four months later the orthosis was removed. The neurological examination, MR scan and electroencephalograph were normal at the final follow-up five months later.

\section{Discussion}

There have been an increasing number of papers describing complications associated with the halo vest with pin track infections, leakage of the cerebrospinal fluid ${ }^{1}$ and even pneumoencephal. ${ }^{2}$ However, traumatic perforation of the skull with no infection is rare. ${ }^{3}$

The screws in the skull must be tightened, because of physiological osteolysis, unless there is a suspicion of infection with late loosening of a pin. In these cases the screws should be replaced in a different position. ${ }^{2}$ Despite the safety mechanism of the torque wrench which does not allow the pins to be over-tightened, in our patient the dorsal screw perforated the internal lamina of the skull. Although ankylosing spondylitis is primarily a disease of the spine, it is likely that the quality of bone is deficient, compared with normal bone, as shown 


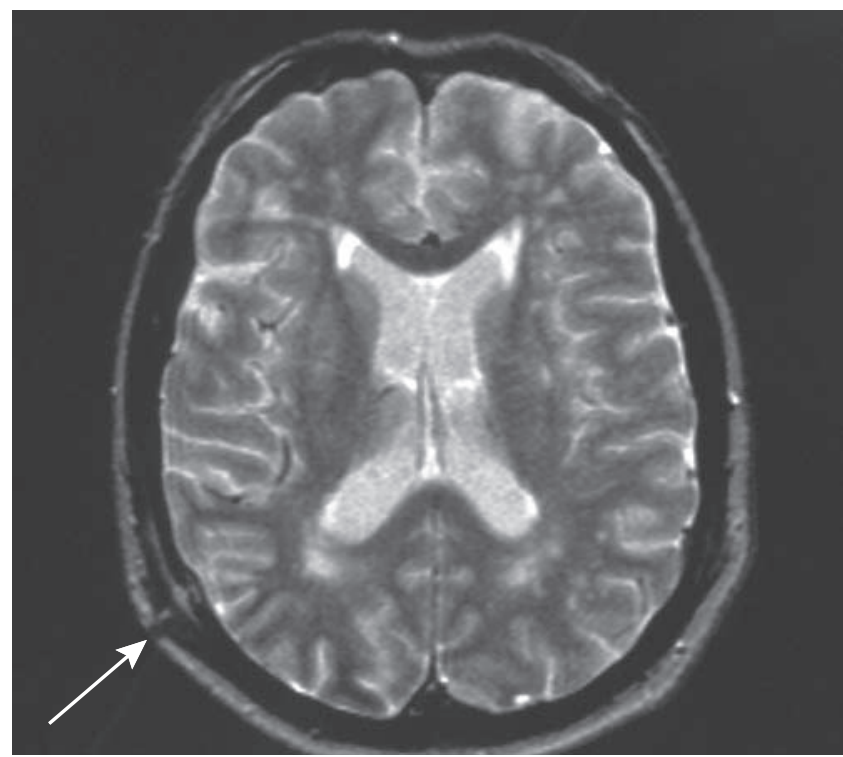

Fig. 1a

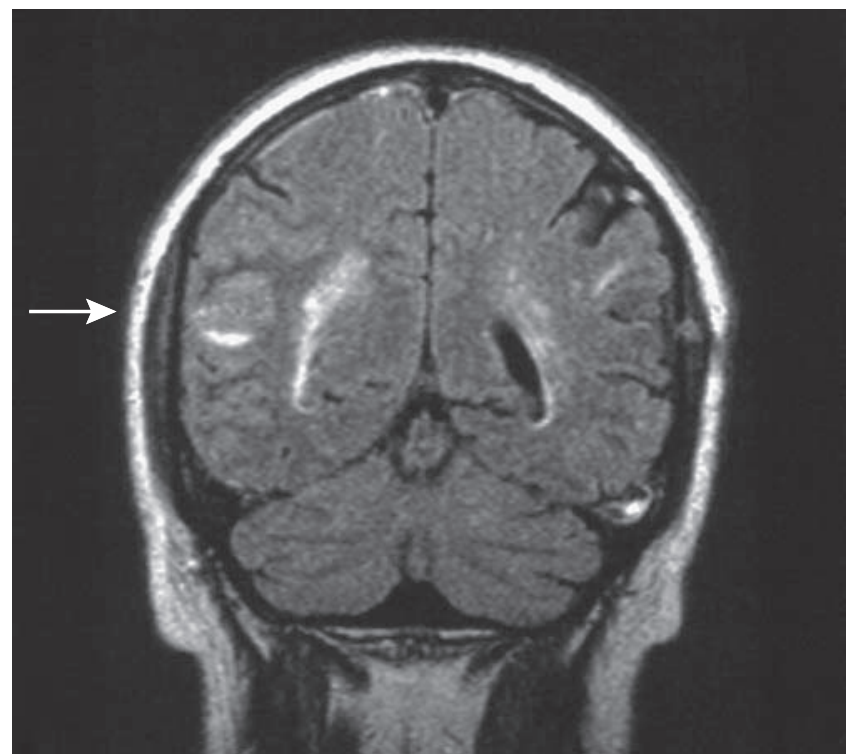

Fig. 1b

MR scan of the brain showing a traumatic swollen cortex under the right dorsal pin track, with a small subarachnoid haematoma.

by Dos Santos et al. ${ }^{4}$ Perforation of the pin, in our patient led to haematoma and he presented two days later with a seizure. It is well known that a traumatic subarachnoid haemorrhage may cause a seizure. ${ }^{5}$ However, a thorough search of the literature did not reveal any reports of a seizure secondary to intracranial penetration of a halo pin.

It is important to realise that a halo pin can cause intracranial damage without a pin track infection. If there is penetration of the pin through the outer cortex, the pin should be removed or replaced. Finally, when patients with a halo vest demonstrate neurological abnormalities, complications of cerebral origin should be considered as well as those of cervical origin.
No benefits in any form have been received or will be received from a commercial party related directly or indirectly to the subject of this article.

\section{References}

1. Glaser JA, Whitehill R, Stramp WG, Jane JA. Complications associated with the halo-vest: a review of 245 cases. J Neurosurg 1986;65:762-9.

2. Hashimoto Y, Doita M, Hasuda K, Korosue K. Intracerebral pneumocephalus and hemiparesis as a complication of a halo vest in a patient with multiple myeloma: case report. J Neurosurg Spine 2004;100:367-71.

3. Garfin SR, Botte MJ, Waters RL, Nickel VL. Complications in the use of the halo fixation device. J Bone Joint Surg [Am] 1986;68-A:320-5.

4. Dos Santos FP, Constantin A, Laroche M, et al. Whole body and regional body mineral density in ankylosing spondylitis. J Rheumatol 2001;28:547-9.

5. Vespa P. Continuous EEG monitoring for the detection of seizures in traumatic brain injury, infarction, and intracerebral hemorrhage: "to detect and protect". J Clin Neurophysiol 2005;22:99-106. 